\title{
Degree of satisfaction among hearing aid users
}

Maria Fernanda Capoani Garcia Mondelli', Andressa Vital Rocha², Heitor Marques Honório'.

\author{
1) Professor. \\ 2) Student (fourth-year undergraduate). \\ Institution: Bauru School of Dentistry - University of São Paulo. \\ Bauru / SP - Brazil. \\ Mailing address: Maria Fernanda Capoani Garcia Mondelli - Al Dr. Octávio P. Brisolla, 9-75 - Vila Universitária Bauru - Bauru / SP - Brazil - Zip code: 17012-901 - E-mail \\ mfernandamondelli@hotmail.com \\ FAPESP - Processo No. 2010/14816-4 \\ Article received on July 5, 2012. Article accepted on September 11, 2012
}

\section{SUMMARY}

Introduction: Hearing loss (HL) is defined as the complete or partial loss of hearing ability.

Aims: To characterize (1) the degree of satisfaction among adult and elderly hearing aid (HA) users who were treated by a public hearing health service and (2) the relationship between satisfaction and the variables of gender, age, degree of HL, and type of HA.

Method: The clinical and experimental study included the administration of the Satisfaction with Amplification in Daily Life (SADL) questionnaire to 110 patients who had used HAs for more than 3 months and were 18 years of age or older.

Results: Test patients were sex-balanced ( $48 \%$ were women) and had a mean age of 67 years. A relatively high incidence of sensorineural moderate HL was detected in the study patients (66\%) and device B was the most commonly used HA type (48\%). No significant differences were evident between HA satisfaction and sex. The importance placed on services/costs and personal image varied between age groups. Correlation was evident at all levels between user satisfaction and amplification. Decreased satisfaction was observed in individuals with severe and/or profound HL. The type of HA used yielded statistically significant differences in the positive effects referring.

Conclusion: No correlations were evident between the different factors proposed. HA users exhibited high levels of satisfaction in all SADL areas.

Keywords: hearing loss, hearing aids, patient satisfaction.

\section{INTRODUCTION}

Hearing loss (HL) can be defined as complete or partial loss of the ability to hear and understand information, which limits or restricts an individual's ability to perform hearing-related activities. The hearing handicap also affects non-auditory skills; such individuals are less able to perform normal everyday activities, which affects their relationships with family, work, and society (1).

To alleviate this stigma and enable an increased quality of life, doctors and professionals recommend the use of a hearing aid (HA) for hearing-impaired individuals (2).

In 2000, the Brazilian Ministry of Health standardized the Secretary of Attention to Health Ordinance No. 432 (3), which focuses on the importance of hearing impairment and social consequences, and the need to extend HA concessions to patients in the Unified Health System.

With the intent of enhancing hearing care, the National Policy for Attention to. Hearing Health Care was instituted through Decrees No. 2073 (4) GM and SAS No. 587 in 2004 (5). This policy provides intervention measures throughout the natural history of HL by integrating several actions, including health promotion, specific protection, treatment (HA concessions when indicated), and rehabilitation.

HA selection should be based on audiological factors (degree and configuration of HL) and physical factors (anatomical characteristics of the pinna and external auditory canal, user's manual dexterity, and medical contraindications for occlusion of the external auditory canal) (6).

The benefits to HA users are related to improved communication in daily life, which reduces disability and handicap. Improved hearing ability, however, extends far beyond hearing and communication benefits (7); satisfaction is a more accurate measure of positive results because it encompasses a constellation of dynamic factors and is dependent on user perception and attitudes in many areas, including those unrelated to HA performance (7-9).

HA users have identified several variables important to the adaptation process, such as comfort, the mold or fit, hearing ability in quiet environments, conversability in noisy environments, sound quality, technical support, and ease of HA cleaning, operation, and insertion $(7,10)$. 
The benefits and disabilities in hearing-impaired individuals using HA can be measured objectively with formal speech recognition tasks and subjectively based on user perception of benefits and difficulties in day-to-day activities. Due to the imperfect relationship between patient perceptions and objective actions, subjective measures have been accepted for clinical application (11).

HAs are adjusted according to patient needs; however, a patient may report discomfort with the use of amplification. Thus, the degree of individual satisfaction in daily communications must be considered, which ensures that acceptance or rejection is based on subjective perceptions (11).

A method to assess the degree of user satisfaction related to HA use is to distribute self-assessment questionnaires. The variable benefit of amplification itself relates directly to performance, but satisfaction is a variable that includes several important factors associated with positive results linked to $\mathrm{HA}$ adjustments and other aspects such as personal stigma and the quality of service provided by the healthcare professional.

The Satisfaction with Amplification in Daily Life (SADL) questionnaire was created to quantify satisfaction achieved by the use of amplification and to measure its primary constituents (7). The psychometric properties for this questionnaire have been confirmed by a study that used it to validate HA user satisfaction.

The SADL was developed to provide an index of overall satisfaction and to identify problem areas that lead to user dissatisfaction (9).

Despite the profound technological advancements in amplification systems, audiologists continue to encounter issues with user satisfaction and contend with high rates of HA abandonment, which poses a problem for health services (9). It is not uncommon for patients who have benefited from HA use to report dissatisfaction with the HA. In contrast, some patients do not exhibit good performance with amplification; however, they report great satisfaction regarding HA use (12).

The reasons described shouldencourage professionals to evaluate self-assessment questionnaires to verify benefits beyond the clinical setting by considering the subject holistically and not their hearing difficulties alone.

This study evaluated (1) the degree of satisfaction among HA users who attended a public health service event on hearing and (2) the relationship between user satisfaction and the variables sex, age, degree of HL, and HA type.

\section{METHOD}

A cross-sectional clinical study was developed after we received approval from the Committee of Ethics in Research (Process No. 110/2010) and patient consent for study participation.

\section{Subjects}

We evaluated 110 patients of both sexes who were 18 years of age or older, had been fitted with and used HAs for a minimum of 3 months, and used a complex service. The subjects indicated their understanding of the hearing threshold required for the implementation of the SADL questionnaire.

To classify HL audiometric thresholds, we used frequencies of 500, 1000, 2000, and $4000 \mathrm{~Hz}$, and characterized HL as mild (average, 26-40 dB), moderate (average, 41-60 dB), severe (average, 61-80 dB) or profound (average, $81 \mathrm{~dB}$ or greater) (13).

HA types were characterized as Class A, B, or C based on the Public Health System and Ministry of Health classifications (5): Class A signals are processed linearly, Class B devices are digital and may or may not be programmable with a WDRC compression system, and Class $\mathrm{C}$ devices are non-linear, digital HAs.

\section{Instrument}

The questionnaire contains 15 questions divided into 4 subscales: positive effects ( 6 items associated with acoustic and psychological benefits), services and costs (3 items associated with professional competence, product price, and number of repairs), negative factors ( 3 items related to environmental noise amplification, feedback, and telephone use), and personal image ( 3 items related to aesthetic factors and the stigma of HA use).

The questionnaire poses closed questions with 7 response options: "no", "very little", "little", "medium", "sometimes", "almost always", and "always". Answers are equivalent to a 7-point scale, where the lowest score is 1 and corresponds to "no," and the highest score is 7 , corresponding to "always", and which indicate the lowest and highest grades of satisfaction, respectively. Questions 2, 4, 7, and 13 correspond to "reverse" items, in which a score of 7 corresponds to "no" and a score of 1 corresponds to "always."

The questionnaire was conducted by the researcher as an oral presentation during individual interviews. The 
direct contact with subjects minimized the possibility of conflicting results and prevented blank responses.

After the SADL scale was applied, the results were scored 1-7; higher scores indicated greater satisfaction (7). The sum of points according to each subscale resulted in a total score of 21 points; however, to differentiate the positive effect between each subscale (maximum score, 42), we set the global maximum score to 105 points. Thus, we calculated the scores based on 4 subscales (positive effect [PE], negative factors [NF], service and cost [SC], and personal image [PI]) and additional analysis that addressed global scores (GBL), which were converted into points and assigned to the 15 questions in the questionnaire.

\section{Statistical analysis}

The quantitative variables related to patient satisfaction were assessed by the degree of HL (mild, moderate, severe, or profound), and the type of HA (A, B, or C) for each of the 5 subscales of the questionnaire (GBL, PE, SC, PI, and NF) was tested using a normal distribution (Shapiro-Wilk test). In all cases, a normal distribution did not emerge $(\mathrm{P}<0.05)$. Therefore, the data were subjected to the nonparametric Kruskal-Wallis test to verify potential differences between the variables that were used to assess patient satisfaction. If statistically significant differences were observed by the Kruskal-Wallis test, a multiple comparison test (Dunn test) was conducted to verify the groups that differed. A 5\% significance level was adopted for all situations.

The $t$-test for independent samples (parametric test) was used to assess potential differences between sexes (male and female) for each of the 5 subscales on the questionnaire $(\mathrm{P}<0.05)$.

Furthermore, Pearson's correlation coefficient was used to evaluate potential correlation with age for each of the 5 subscales on the questionnaire $(\mathrm{P}<0.05)$.

\section{RESULTS}

The study population was nearly balanced in regard to sex (48.18\% were women), and the mean age was 67 years. Sensorineural moderate HL yielded the highest incidence, with 66.36\% exhibiting asymmetrical HL ( 1 ear was better for testing HA performance). Type B HAs were used most frequently (48.18\%).

The user satisfaction scores are presented according to sex and age in Tables 1 and 2, respectively.
Table I. Comparison between sexes for each of the 5 assessed subscales.

\begin{tabular}{lcccc}
\hline Subscale & Gender & $\begin{array}{c}\text { Average } \\
\text { (scale, I-7) }\end{array}$ & $\begin{array}{c}P \\
\text { (sex-specific) }\end{array}$ & $P^{*}$ \\
\hline GBL & $M$ & 6.110526 & 0.432470 & 0.318540 \\
& $F$ & 6.013208 & 0.515613 & \\
PE & $M$ & 6.750877 & 0.396918 & 0.312799 \\
& $F$ & 6.662264 & 0.515613 & \\
SC & $M$ & 5.250140 & 0.614996 & 0.246766 \\
& $F$ & 5.120755 & 0.602992 & \\
NF & $M$ & 5.685965 & 1.168858 & 0.237563 \\
& $F$ & 5.381132 & 1.512010 & \\
PI & $M$ & 6.108772 & 1.085173 & 0.822727 \\
& $F$ & 6.154717 & 1.057858 & \\
\hline
\end{tabular}

*P $<0.05$ indicates statistically significant differences between sexes for each of the subscales ( $t$-test for independent samples).

GBL, global; PE, positive effect; SC, services costs; NF, negative factors; PI, personal image; M, male; F, female.

Table 2. Comparison between ages within each of the 5 subscales based on Pearson's correlation coefficient.

\begin{tabular}{lcc}
\hline Subscale & $R$ & $P^{*}$ \\
\hline GBL & -0.013494 & 0.888730 \\
PE & -0.071517 & 0.457808 \\
SC & -0.211803 & 0.026331 \\
NF & -0.087985 & 0.360702 \\
PI & 0.247237 & 0.009215 \\
\hline
\end{tabular}

$* \mathrm{P}<0.05$ indicates correlation between variables.

$\mathrm{R}$, Pearson's correlation coefficient value.

GBL, global; PE, positive effect; SC, services and costs; NF, negative factors; PI, personal image.

Tables 3 and 4 present user satisfaction related to the degree of HL and the category of HA, respectively.

\section{DISCUSSION}

The results of the questionnaire revealed high levels of HA user satisfaction.

No significant differences in HA user satisfaction were observed for sex by any aspect of the SADL (Table 1). In addition, there was a predominance of men in the studied sample, and the data corresponded to another study (14) in which the predominant sex was female. These results demonstrate consistent responses to questions posed to both sexes. 
Table 3. Degree of hearing loss within each of the 5 subscales.

\begin{tabular}{|c|c|c|c|c|c|c|}
\hline Subscale & Group & $\begin{array}{l}\text { Firstquartile } \\
\text { (scale, } 1-7 \text { ) }\end{array}$ & $\begin{array}{c}\text { Median } \\
\text { (scale, } 1-7 \text { ) }\end{array}$ & $\begin{array}{l}\text { Third quartile } \\
\text { (scale, } \mid-7 \text { ) }\end{array}$ & $\begin{array}{c}\text { Average } \\
\text { (scale, } \mid-7 \text { ) }\end{array}$ & $\begin{array}{c}\text { StandardDeviation } \\
\text { (scale, } \mid-7 \text { ) }\end{array}$ \\
\hline \multirow[t]{4}{*}{$\overline{\mathrm{GBL}}$} & $M$ & 5.900 & $6.100 \mathrm{ab}$ & 6.400 & 6.074 & 0.477 \\
\hline & $\mathrm{S}$ & 6.075 & $6.250^{a}$ & 6.500 & 6.236 & 0.357 \\
\hline & $\mathrm{m}$ & 5.100 & $6.200 \mathrm{ab}$ & 6.550 & 5.822 & 0.920 \\
\hline & $\operatorname{Pr}$ & 5.300 & $5.700^{b}$ & 5.950 & 5.667 & 0.320 \\
\hline \multirow[t]{4}{*}{ PE } & $M$ & 6.700 & $6.800^{a}$ & 7.000 & 6.721 & 0.415 \\
\hline & $S$ & 6.775 & $6.800^{a}$ & 7.000 & 6.764 & 0.343 \\
\hline & $\mathrm{m}$ & 6.400 & $6.800^{a}$ & 7.000 & 6.456 & 0.951 \\
\hline & $\operatorname{Pr}$ & 6.650 & $6.650^{a}$ & 6.850 & 6.733 & 6.733 \\
\hline \multirow[t]{4}{*}{ SC } & $M$ & 5.000 & $5.000^{\mathrm{a}}$ & 5.500 & 5.182 & 0.627 \\
\hline & $S$ & 5.000 & $5.000^{a}$ & 6.000 & 5.318 & 0.637 \\
\hline & $\mathrm{m}$ & 5.000 & $5.000^{a}$ & 5.000 & 5.000 & 0.500 \\
\hline & $\operatorname{Pr}$ & 4.925 & $5.000^{a}$ & 5.250 & 5.117 & 0.449 \\
\hline \multirow[t]{4}{*}{ NF } & $M$ & 5.700 & $5.700^{a}$ & 6.700 & 5.542 & 1.316 \\
\hline & $\mathrm{S}$ & 6.300 & $6.300^{\mathrm{a}}$ & 6.700 & 5.900 & 1.059 \\
\hline & $\mathrm{m}$ & 6.000 & $6.000^{a}$ & 7.000 & 5.478 & 1.879 \\
\hline & $\operatorname{Pr}$ & 3.800 & $3.800^{a}$ & 5.200 & 4.267 & 1.335 \\
\hline \multirow[t]{4}{*}{$\mathrm{Pl}$} & $M$ & 5.000 & $6.700^{a}$ & 7.000 & 6.151 & 1.094 \\
\hline & S & 5.925 & $7.000^{\mathrm{a}}$ & 7.000 & 6.427 & 0.837 \\
\hline & $\mathrm{m}$ & 4.350 & $6.000^{a}$ & 7.000 & $5.7 \mid 1$ & 1.296 \\
\hline & $\operatorname{Pr}$ & 4.825 & $5.300^{\mathrm{a}}$ & 6.175 & 5.433 & 0.829 \\
\hline
\end{tabular}

Different superscript letters indicate statistically significant different levels of hearing loss among the subscales (Kruskal-Wallis test followed by Dunn's test).

GBL, global; PE, positive effect; SC, services and costs; NF, negative factors; PI, personal image; M, moderate hearing loss; $\mathrm{S}$, severe hearing loss; $\mathrm{m}$, mild hearing loss; Pr, profound hearing loss

Table 4. Comparison among the 5 categories of hearing aid subscales.

\begin{tabular}{lcccccc}
\hline Subscale & Group & $\begin{array}{c}\text { Firstquartile } \\
(\text { scale, I-7) }\end{array}$ & $\begin{array}{c}\text { Median } \\
(\text { scale, I-7) }\end{array}$ & $\begin{array}{c}\text { Thirdquartile } \\
(\text { scale, I-7) }\end{array}$ & $\begin{array}{c}\text { Average } \\
(\text { scale, I-7) }\end{array}$ & $\begin{array}{c}\text { StandardDeviation } \\
(\text { scale, I-7) }\end{array}$ \\
\hline GBL & A & 5.700 & $5.900^{a}$ & 6.400 & 5.947 & 0.497 \\
& B & 5.900 & $6.100^{a}$ & 6.400 & 6.068 & 0.459 \\
& C & 6.000 & $6.300^{a}$ & 6.500 & 6.116 & 0.581 \\
PE & A & 6.500 & $6.700^{a}$ & 6.800 & 6.611 & 0.408 \\
& B & 6.700 & $6.800^{a}$ & 7.000 & 6.738 & 0.375 \\
& C & 6.800 & $7.000^{a}$ & 7.000 & 6.716 & 0.577 \\
SC & A & 5.000 & $5.000^{a}$ & 5.000 & 5.068 & 0.116 \\
& B & 5.000 & $5.000^{a}$ & 6.000 & 5.202 & 0.104 \\
& C & 5.000 & $5.000^{a}$ & 5.500 & 5.237 & 0.065 \\
NF & A & 5.700 & $5.700^{a}$ & 6.300 & 5.363 & 1.289 \\
& B & 5.700 & $5.700^{a}$ & 6.700 & 5.449 & 1.465 \\
& C & 6.000 & $6.000^{a}$ & 7.000 & 5.753 & 1.204 \\
PI & A & 5.000 & $6.700^{a}$ & 7.000 & 6.037 & 1.107 \\
& B & 5.125 & $6.700^{a}$ & 7.000 & 6.160 & 0.938 \\
& C & 5.125 & $7.000^{a}$ & 7.000 & 6.137 & 1.232
\end{tabular}

${ }^{*}$ Different superscript letters indicate statistically significant differences among the types of hearing aids used in each of subscales (Kruskal-Wallis testfollowed by Dunn'stest).

GBL, global; PE, positive effect; SC, services and costs; NF, negative factors; PI, personal image 
With regard to age and the degree of user satisfaction, significant values emerged for SC and PI, indicating decreased satisfaction in these subscales (Table 2). A consensus emerged for the decline of auditory function due to the deterioration of hearing sensitivity inherent to the aging process; HL becomes more pronounced at high frequencies and occurs more rapidly in men. HL occurs more frequently in men than in women, which may be related to male participation in lifelong occupational activities (15).

Of the 110 subjects evaluated in this study, $75 \%$ were over the age of 60 years, which introduces the possible need for a statistical study that correlates age and satisfaction with the use of amplification.

For correlation between the degree of HL and user satisfaction subscales (PE, SC, NF, and PI), the differences between treatment groups (median values) were not sufficiently large to exclude the possibility that the result was due to random sample variability. No significant differences were evident for most items with regard to satisfaction and degree of HL. The only considerable value occurred between the GBL and degree of HL (Table 3).

The differences in the median values between GBL and HL were significantly different. Thus, a multiple comparison procedure was used to isolate the subgroup from the others, and the same significance was observed between severe and profound HL in relation to the values assigned in the overall score. HA user satisfaction in relation to all degrees of HL was identified; however, we observed lower satisfaction in the GBL for individuals with severe and/or profound HL.

No studies were found in the literature that specifically assessed the satisfaction of HA users with severe and profound HL, perhaps because these selection criteria often are not included for auditory thresholds that trigger the application of these questions.

Individuals with pronounced degrees of HL benefit from HA use because HAs are an integral part of day-to-day and essential communication in these users. Subjects believed the HA represents the best option to reduce difficulties and permit greater feelings of capability and satisfaction (16).

The most common complaint from individuals of all ages was related to difficulty understanding spoken language and oral communication, mainly within unfavorable communication situations such as noisy environments or increased speech rates.
The satisfaction related to HA product type was obtained from sample variable scores for various scales. The variable referred to the profile of electroacoustic devices; similar studies have found no significant results (17).

With respect to the subscales of the questionnaire, the results indicated greater satisfaction on the PE subscale for all degrees of HL and all types of HAs; a maximum score was attained for type C HAs. Greater satisfaction was recorded among individuals with varying degrees of HL and HA types in relation to the PI subscale. A smaller satisfaction subscale was recorded for NF, which ranged the non-demoted scores related to the degree of HL (the worst was for profound loss) and the values assigned to the instrument type.

This evaluation became crucial to HA user status in relation to standard services for selecting and fitting HAs; the analysis of group performance can lead to the creation of new service strategies.

In general, all 110 individuals interviewed in this study exhibited some degree of satisfaction with HA use, greater than that determined by the established standardization (8), for all categories of the questionnaire.

These results are similar to those from another study (18) that revealed significant differences for the subscales PE, SC, and NF, and for the overall score. The only subscale for which a significant difference did not result was PI.

The SADL questionnaire has been used successfully in several countries $(19,20)$, which indicates the extreme importance of HA verification steps. Patient opinion, however, becomes critical to subsequent adjustments and effective use of amplification.

The study collection was diverse and widely distributed, especially in the PI subscale, which indicates that at present, patients do not associate the use of electronic devices with a negative image that corresponds to disability. HL is becoming common in a society that has begun to change its concepts and its vision of disability in general, facilitating acceptance of deaf people and their limitations without perception that HL is an impediment to the exercising of their functionality.

\section{CONCLUSION}

HA users exhibited high rates of satisfaction in all areas of the SADL without emphasis on any particular subscales. 


\section{REFERENCES}

1. World Health Organization-WHO/OMS. [texto na internet]. 2009. [acesso em 05 de julho de 2010]. Disponível em: http:/ /www.who.int/en/

2. Andrade CF, Blasca WQ. A satisfação do usuário de aparelho de amplificação sonora individual com a tecnologia digital. Salusvita. 2005;24(2):257-65.

3. Brasil. Ministério da Saúde. Portaria no 432, de 14 de novembro de 2000. Institui a política nacional de atenção à saúde auditiva Disponível em: <http:// dtr2001.saude.gov.br/sas/PORTARIAS/PORT2000/ PT432.htm>.

4. Brasil. Ministério da Saúde. Portaria nº 2.073/GM de 28, de setembro de 2004. Institui a política nacional de atenção à saúde auditiva. Disponível em: Carvalho $\mathrm{SA}<\mathrm{http}: / /$ dtr2001.saude.gov.br/sas/PORTARIAS/PORT2004/GM/ GM-2073.htm>.

5. Brasil. Ministério da Saúde. Distribuição da rede estadual para ações na atenção básica, na média e alta complexidade, portaria SAS/MS n. .587 de 07/10/2004. www.saude.gov.br. 2005.

6. Campos CAH, Russo ICP, Almeida K. Indicação, seleção e adaptação de próteses auditivas: princípios gerais. In: Almeida K, Iório MCM. Próteses auditivas fundamentos teóricos e aplicações clinicas. Lovise. 2003.

7. Cox RM, Alexander GC. Measuring satisfaction with amplification in daily life: the SADL scale. Ear Hear. 1999;20(4):306-20.

8. Hosford-Dunn H, Halpern J. Clinical application of the satisfaction with amplification in daily life scale in private practice I: statistical, content, and factorial validity. J Am Acad Audiol. 2000;11(10): 523-39.

9. Veiga LR, Merlo ARC, Mengue SS. Satisfação com a prótese auditiva na vida diária em usuários do Sistema de Saúde do Exército. Rev Bras Otorrinolaringol. 2005;71(1):67-73.

10. Cox RM, Alexander GC. Expectations about hearing aids and their relationship to fitting outcome. J Am Acad Audiol. 2000;11(7):368-82.
11. Almeida K, Taguchi CK. Utilização do questionário na auto-avaliação do benefício das próteses auditivas. Pró-Fono. 2004;16(1):101-10.

12. Assayag FHM, Russo ICP. Avaliação subjetiva do benefício e dos efeitos proporcionados pelo uso de amplificaçãosonora em indivíduos idosos. Rev Dist Comum. 2006;18(3):383-90.

13. WHO-World Health Organization. Grades of Hearing impairment, 2007 [acesso em 26 de fevereiro de 2010]. Disponível em : http://www.who.int/pbd/desfness/ hearing_impairment_grades/en/index.html.

14. Soares DO, Tavares RA, Ferreira RT, Guglielmino G, Dinato C, Franchi VM. Satisfação dos usuários de prótese auditiva em seu dia-a-dia. ACTA ORL. 2007;25(4):290-92.

15. Pinzan-Faria VM, Iorio MCM. Sensibilidade auditiva e autopercepção do handicap: um estudo em idosos. Distúrbios da Comunicação, São Paulo, 2004;16(3): 28999.

16. Lessa AH, Costa MJ, Becker KT, Vaucher VA. Satisfação de Usuários de Próteses Auditivas, com Perda Auditiva de Graus Severo e Profundo. Arq Int Otorrinolaringol. 2010;14(3):338-45.

17. Farias RB, Russo ICP. Saúde auditiva: estudo do grau de satisfação de usuários de aparelho de amplificação sonora individual. Rev Soc Bras Fonoaudiol. 2010;15(1):2631.

18. Mcleod B, Upfold L, Broadbent C. An investigation of the applicability of the inventory, satisfaction with amplification in daily life, at 2 weeks post hearing aid fitting. Ear Hear. 2001;22(4):3427.

19. Kam ACS. Hearing-aid outcomes in Chinese adults: Clinical application and psychometric properties of the Chinese version of the Satisfaction with Amplification in Daily Life questionnaire. Int J of Audiol. 2012;51:450-5.

20. Meister H, Grugel L, Meis M, Kiessling J. Use of selfassessment inventories in hearing-aid provision: German versions of ECHO and SADL. Int J of Audiol. 2012;51:13542. 